\title{
Tests of renal function in patients with quiescent colitis: effects of drug treatment
}

\author{
S A Riley, D R Lloyd, V Mani
}

\begin{abstract}
Mesalazine has structural similarities to aspirin and phenacetin and is nephrotoxic when given intravenously in high doses to rats. A number of cases of nephrotoxicity has been reported recently in patients taking oral mesalazine. Sensitive indicators of renal function in a group of patients maintained on long term, delayed release mesalazine and a comparable group on sulphasalazine have been studied. Sixty two patients ( 32 men, aged 28-82 years) with quiescent colitis were studied. Thirty four had been maintained on delayed release mesalazine $1.6(0.8-2.4) \mathrm{g} /$ day for $2.9(0.5-6.9)$ years and 28 on sulphasalazine 2 (2-3) g/day. Groups were comparable for age, sex, disease duration, and disease extent. Renal function was assessed by: urine microscopy; creatinine clearance; the urinary excretion of two markers of glomerular toxicity, albumin and transferrin; and the urinary excretion for two markers of tubular toxicity, $\mathbf{N}$-acetyl- $\beta$-D-glucosaminidase (NAG) and $\alpha_{1^{-}}$ microglobulin. There were no significant differences in renal function between the two treatment groups. Furthermore, no correlations were found between measures of renal function and either cumulative mesalazine dose or mesalazine treatment duration. In this study, long term maintenance treatment with delayed release mesalazine was no more nephrotoxic than continued treatment with sulphasalazine.
\end{abstract}

(Gut 1992; 33: 1348-1352)

Recent insights into the pharmacology and component properties of sulphasalazine have led to the development of a new generation of drugs based on mesalazine (5-aminosalicylic acid, 5-ASA). These agents seem as effective as sulphasalazine in the treatment of patients with ulcerative colitis, and in the short term are less toxic.' However, considerations of long term safety are also important as lifelong maintenance treatment is usually recommended.

The effect of mesalazine treatment on renal function has been a particular concern as mesalazine has structural similarities to aspirin and phenacetin, both of which have been implicated in analgesic nephropathy. ${ }^{3}$ Chronic sulphasalazine treatment does not seem to be nephrotoxic but the systemic absorption of 5-ASA from sulphasalazine is relatively low. ${ }^{4}$ Delayed release mesalazine formulations release their contents rapidly in the distal small intestine and proximal colon. Plasma concentrations of 5-ASA may therefore be higher in patients taking delayed release mesalazine than in patients taking equivalent doses of sulphasalazine. ${ }^{5}$ In addition, freedom from sulphapyridine related side effects allows high dose treatment, further increasing the potential for dose related nephrotoxicity. We have therefore studied sensitive indicators of renal function in patients maintained on long term, delayed release mesalazine and a comparable group maintained on sulphasalazine.

\section{Methods}

PATIENT SELECTION AND ASSESSMENT

Patients were selected from a computerised database of 222 patients with chronic ulcerative colitis attending Leigh Infirmary. Of these, 44 had been taking delayed release mesalazine as the sole maintenance treatment for at least six months. For each patient taking mesalazine a computer matched patient taking sulphasalazine was also selected. All pairs were matched for age (within five years), sex, disease duration (within five years), and disease extent.

Patients were invited to participate by letter and those who consented attended for outpatient review. Patients with symptoms of active colitis in the four weeks before attendance and those with a history of diabetes, hypertension, renal disease, or chronic analgesic ingestion were excluded. A detailed drug history was taken to confirm the type, dose, and duration of maintenance medication.

At the time of clinic attendance patients were asked to provide a freshly voided sample of urine for microscopy and to return with a timed urine collection for measurement of: (i) creatinine clearance; (ii) two markers of glomerular toxicity, albumin and transferrin excretion ${ }^{67}$; and (iii) two markers of tubular toxicity, $\alpha_{1}$ microglobulin and $\mathrm{N}$-acetyl- $\beta$-D-glucosaminidase (NAG) excretion. ${ }^{89}$

To overcome the problems of collecting a 24 hour urine specimen, an overnight collection was made. ${ }^{10}$ This had the added advantage of controlling for circadian variations in creatinine clearance $^{11}$ and minimised the effects of postural fluctuations in urinary protein excretion. ${ }^{12}$ Patients were asked to empty their bladder before going to bed, noting the precise time and discarding the urine. Urine passed through the night was saved and on rising the bladder was again emptied, the urine saved, and the exact time noted. Patients were asked to return the collection at 9 am the same morning, at which time a $10 \mathrm{ml}$ blood sample was taken. Aliquots of urine and plasma were stored at $-20^{\circ} \mathrm{C}$ before analysis.

In order to establish appropriate normal values for overnight creatinine clearance and marker excretion, 50 age matched healthy volunteers were studied using an identical protocol. 
ANALYTICAL TECHNIQUES

Plasma and urinary creatinine concentrations were measured using the Jaffe reaction. ${ }^{13}$

Urinary albumin concentrations were measured by immunoturbidimetry. In brief, a 25 $\mu \mathrm{l}$ urine sample was added to $250 \mu \mathrm{l}$ of rabbit antiserum to human albumin (Dakopatts, DK2600 ) in buffer. The change in absorbance at 340 nm was measured between 0.5 and 100 seconds and results were derived from absorbance changes produced by eight standard solutions (American Hospital Supply, UK). The range of the assay was 3 to $180 \mathrm{mg} / \mathrm{l}$ and between and within batch coefficients of variation were 5.0 and $2 \cdot 7 \%$ respectively. ${ }^{14}$

Transferrin concentrations were determined by enzyme immunoassay. ${ }^{15}$ Microtitre plate wells were coated with $100 \mu \mathrm{l}$ of anti-human transferrin (Dakopatts) in $0.05 \mathrm{M}$ carbonate bicarbonate buffer ( $\mathrm{pH} 9.6)$ at a concentration of $10 \mu \mathrm{g} / \mathrm{ml}$. Plates were incubated for one hour at room temperature and then overnight at $4^{\circ} \mathrm{C}$. After emptying and washing each well, $100 \mu \mathrm{l}$ of sample or standard (diluted 1 in 80 in phosphate buffered saline, $\mathrm{pH} 7 \cdot 2$, and containing $0 \cdot 1 \%$ Tween and $0.5 \%$ bovine serum albumin to prevent non-specific protein binding to the plate) were added and incubated for one hour. After washing, $100 \mu \mathrm{l}$ of anti-transferrin horseradish peroxidase conjugate in buffer was added at a dilution of 1 in 2000 and incubated for a further 60 minutes. The conjugate buffer contained $0.1 \%$ Tween, $0.5 \%$ bovine serum albumin, and $1.0 \%$ normal rabbit serum to prevent nonspecific binding of conjugate to the plate. After washing, $100 \mu \mathrm{l}$ of substrate (tetramethylbenzidine in DMSO $(10 \mathrm{mg} / \mathrm{ml})$ diluted 1 in 100 in $0.15 \mathrm{M}$ citrate buffer and containing $\mathrm{H}_{2} \mathrm{O}_{2}$ to a final concentration of $1.3 \mathrm{M} / \mathrm{l}$ ) were added and incubated for a further 15 minutes. Finally, 100 $\mu \mathrm{l}$ of $1.0 \mathrm{M}$ sulphuric acid were added to stop the reaction and the absorbance was read at $450 \mathrm{~nm}$. Concentrations were derived by reference to a standard curve (Behring Diagnostics). The range of the assay was 20 to $4000 \mu \mathrm{g} / \mathrm{l}$ and within and between batch coefficients of variation were $3 \cdot 4 \%$ and $6 \cdot 1 \%$ respectively.

$\alpha_{1}$-microglobulin concentrations were measured by enzyme immunoassay using an identical methodology to that described for transferrin. ${ }^{15}$ The range of the assay was $0 \cdot 1$ to $10.0 \mathrm{mg} / \mathrm{l}$ and within and between batch coefficients of variation were $2 \cdot 4 \%$ and $4.9 \%$ respectively.

NAG concentrations were determined colorimetrically using a commercially available kit (Boehringer Mannheim). Briefly, a $15 \mu \mathrm{l}$ urine sample was added to $250 \mu$ l of 3-Cresolsulfonphthaleinyl-N-acetyl- $\beta$-D-glucosamide and incubated at $37^{\circ} \mathrm{C}$ for 11 minutes. The reaction was stopped by the addition of $75 \mu$ l of saturated sodium carbonate and the optical density was read at $580 \mathrm{~nm}$ (Cobas Bioanalyser, Roche). Results were calculated by reference to a standard curve. The between batch coefficient of variation was less than $3 \cdot 0 \%$.
Patient and disease characteristics

\begin{tabular}{lll}
\hline & $\begin{array}{l}\text { Mesalazine } \\
(n=34)\end{array}$ & $\begin{array}{l}\text { Sulphasalazine } \\
(n=28)\end{array}$ \\
\hline Age (years) & $45(31-80)$ & $48(28-82)$ \\
Sex (M:F) & $16: 18$ & $16: 12$ \\
Disease duration (years) & $8(2-27)$ & $9 \cdot 5(3 \cdot 5-21)$ \\
$\begin{array}{l}\text { Disease extent: } \\
\quad \text { Proctitis }\end{array}$ & 11 & 6 \\
$\quad \begin{array}{l}\text { Proctosigmoiditis } \\
\quad \text { Left sided }\end{array}$ & 14 & 11 \\
$\quad 50 t a l$ colitis & 4 & 7 \\
$\begin{array}{l}\text { Treatment duration (years): } \\
\quad \text { Mesalazine }\end{array}$ & $2 \cdot 9(0 \cdot 5-6 \cdot 9)$ & $\mathrm{Nil}$ \\
$\quad$ Sulphasalazine & $4 \cdot 6(0-24)^{\star}$ & $7 \cdot 0(1 \cdot 7-21)$ \\
$\begin{array}{l}\text { Treatment dose (g/day): } \\
\quad \text { Mesalazine }\end{array}$ & $1 \cdot 6(0 \cdot 8-2 \cdot 4)$ & $\mathrm{Nil}$ \\
$\quad$ Sulphasalazine & $2(2-3)^{\star}$ & $2(2-3)$ \\
\hline
\end{tabular}

Results are shown as median and range. ${ }^{\star}$ Duration and dose of sulphasalazine treatment before mesalazine treatment.

unless otherwise stated. Between treatment comparisons were made using signed rank tests and correlations were sought using Spearman's rank correlation test.

\section{Results}

Of the 88 patients invited to participate, 62 fulfilled the inclusion criteria and agreed to the study. Thirty four patients had been maintained on delayed release mesalazine for a minimum of six months and 28 had been maintained on long term sulphasalazine. The two groups were comparable for age, sex, disease duration, and disease extent (Table).

Patients treated with mesalazine had taken the drug for $2.9(0.5-6.9)$ years at a daily dose of 1.6 $(0 \cdot 8-2 \cdot 4) \mathrm{g}$ daily; the total cumulative mesalazine

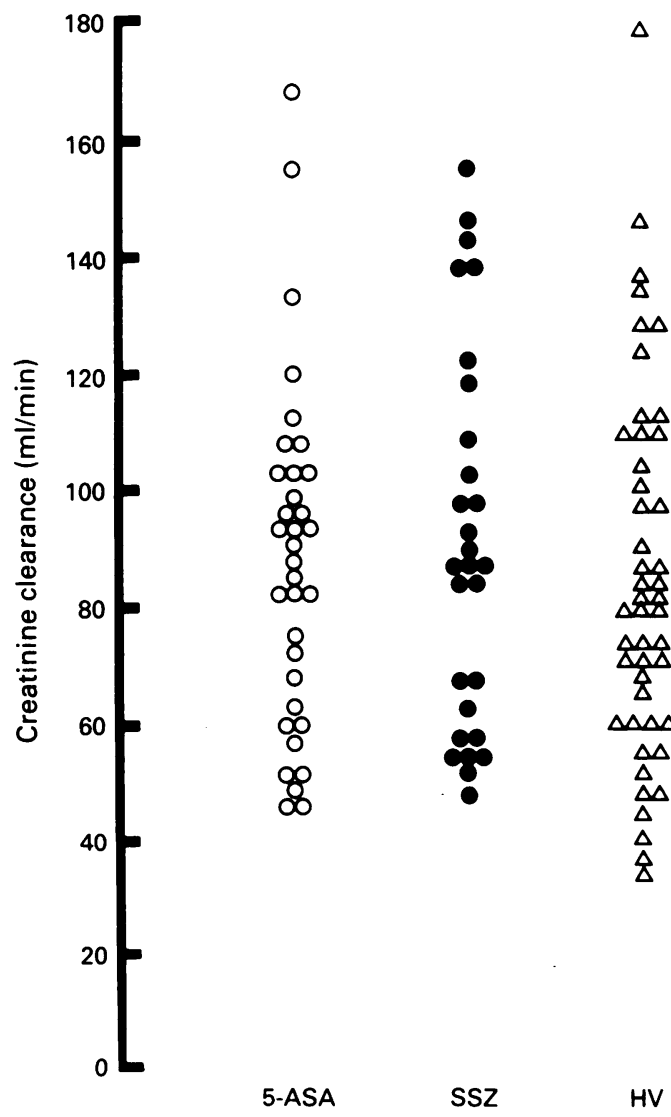

Figure 1: Creatinine clearance in patients maintained on mesalazine (5-ASA) and sulphasalazine $(S S Z)$ and in $a$ group of healthy volunteers $(H V)$. 


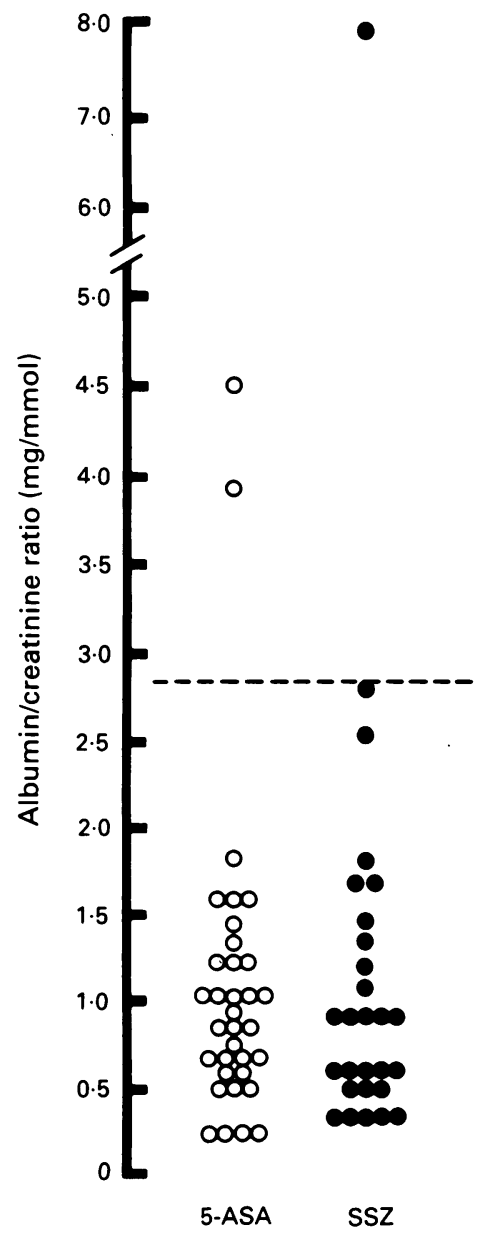

Figure 2: Urinary excretion of albumin and transferrin in patients maintained on mesalazine (5-ASA) and sulphasalazine (SSZ). Results are expressed as marker/creatinine concentration ratios. The upper limit of normal (95th centile) is shown by the dotted line.

dose was $1.46(0 \cdot 58-3 \cdot 50) \mathrm{kg}$. Nine of the group had never received sulphasalazine, the other 25 had been maintained on sulphasalazine $2(2-3) \mathrm{g}$ daily for $4 \cdot 3(0 \cdot 2-24)$ years before mesalazine treatment. Patients in the sulphasalazine group had been maintained on the drug at a daily dose of $2(2-3) \mathrm{g}$ for $8 \cdot 0(1 \cdot 7-2 \cdot 1)$ years and had never received mesalazine. The total duration of maintenance drug treatment was comparable in the two groups.

Urine microscopy was unremarkable in all cases. Creatinine clearance values varied widely but did not differ significantly between the two treatment groups (mesalazine $=90(47-172) \mathrm{ml} /$ $\mathrm{min}$, sulphasalazine $=85(48-153) \mathrm{ml} / \mathrm{min})$ or between the treatment groups and the healthy volunteers (healthy volunteers $=79(34-180 \mathrm{ml}$ min) (Fig 1). A negative correlation between creatinine clearance and age was apparent in all three groups (mesalazine: $\mathrm{r}=-0.44, \mathrm{p}<0.01$; sulphasalazine: $\mathrm{r}=-0.36, \mathrm{p}<0.05$; healthy volunteers: $r=-0.47, p<0.01)$. No significant correlations were apparent between creatinine clearance and either duration of mesalazine treatment or cumulative mesalazine dose.

The results of urinary albumin and transferrin excretion are shown in Figure 2. All results are expressed as marker/creatinine concentration ratios in order to standardise for differences in timing of the urine collection. ${ }^{16}$ In the healthy volunteers the albumin/creatinine ratio was 0.60 $(0-3 \cdot 3) \mathrm{mg} / \mathrm{mmol}$ and the transferrin/creatinine ratio was $17 \cdot 2(2 \cdot 0-161) \mu \mathrm{g} / \mathrm{mmol}$. (The upper limit of normal for each measure was set at the 95th centile). There were no significant differences between the two treatment groups (albumin/creatinine ratio: mesalazine $=0.91$ $(0.23-4.55) \mathrm{mg} / \mathrm{mmol}$, sulphasalazine $=0.84$ $(0.24-7.95) \mathrm{mg} / \mathrm{mmol}$; transferrin/creatinine ratio: mesalazine $=7 \cdot 4 \quad(1 \cdot 1-94) \mu \mathrm{g} / \mathrm{mmol}$, sulphasalazine $=17 \cdot 6 \quad(1-229) \quad \mu \mathrm{g} / \mathrm{mmol})$ or between the treatment groups and healthy volunteers. Four patients had albumin/ creatinine ratios above the 95th centile (two mesalazine, two sulphasalazine) and four patients had mildly raised transferrin/creatinine ratios (one mesalazine, three sulphasalasine). Albumin/creatinine ratios were positively correlated with transferrin/creatinine ratios in both treatment groups (mesalazine $\mathrm{r}=0.44, \mathrm{p}<0.01$; sulphasalazine $\mathrm{r}=0.38, \mathrm{p}<0.05)$ but neither correlated with the duration of mesalazine treatment or cumulative mesalazine dose.

Figure 3 shows the results of $\alpha_{1}$-microglobulin/ creatinine and NAG/creatinine concentration ratios. In healthy volunteers the $\alpha_{1}$ microglobulin/creatinine and NAG/creatinine ratios were $277(12-1237) \mu \mathrm{g} / \mathrm{mmol}$ and 240 (1-755) $\mathrm{mU} / \mathrm{mmol}$ respectively. No significant differences were found between the two treatment groups $\left(\alpha_{1}\right.$-microglobulin/creatinine ratio: mesalazine $=132(3-1070) \mu \mathrm{g} / \mathrm{mmol}$, sulphasalazine $=193(6-2237) \mu \mathrm{g} / \mathrm{mmol}$; NAG/creatinine ratio: mesalazine $=187 \quad(49-1360) \mathrm{mU} / \mathrm{mmol}$, sulphasalazine $=202 \quad(64-650) \mathrm{mU} / \mathrm{mmol})$ or between the treatment groups and healthy volunteers. Five patients had raised $\alpha_{1}$-microglobulin ratios (one mesalazine, four sulphasalazine) and four patients had high NAG ratios (two mesalazine, two sulphasalazine). $\alpha_{1}$-microglobulin/creatinine ratios correlated with NAG/ creatinine ratios in both treatment groups (mesalazine $\mathrm{r}=0.56, \mathrm{p}<0.01$; sulphasalazine $r=0.64, p<0.01$ ) but neither correlated with the duration of mesalazine treatment or cumulative mesalazine dose.

\section{Discussion}

Salicylate nephrotoxicity has been recognised for many years. Acute renal failure is not uncommon after aspirin overdose ${ }^{17}$ and large therapeutic doses of acetyl salicylic acid, choline salicylate, and sodium salicylate may cause acute tubular dysfunction. ${ }^{1819}$ Pathological studies in the rat, however, suggest that tubular necrosis is transient despite continued dosing. ${ }^{20}$

Although aspirin has been implicated in chronic analgesic nephropathy recent studies have cast doubt on this association. ${ }^{21} 22$ Moreover, high dose para-aminosalicylic acid (4-ASA) was, for many years, used in the treatment of tuberculosis yet nephrotoxic reactions were uncommon. In massive dose, however, 4-ASA may cause haematuria and reduce creatinine clearance, particularly in patients with preexisting renal disease. ${ }^{23}$ Similarly, despite widespread clinical use, evidence for sulphasalazine renal toxicity is scanty. Acute interstitial nephritis and nephrotic syndrome have been reported ${ }^{24}$ but evidence of chronic nephropathy is lacking. ${ }^{26}$ 


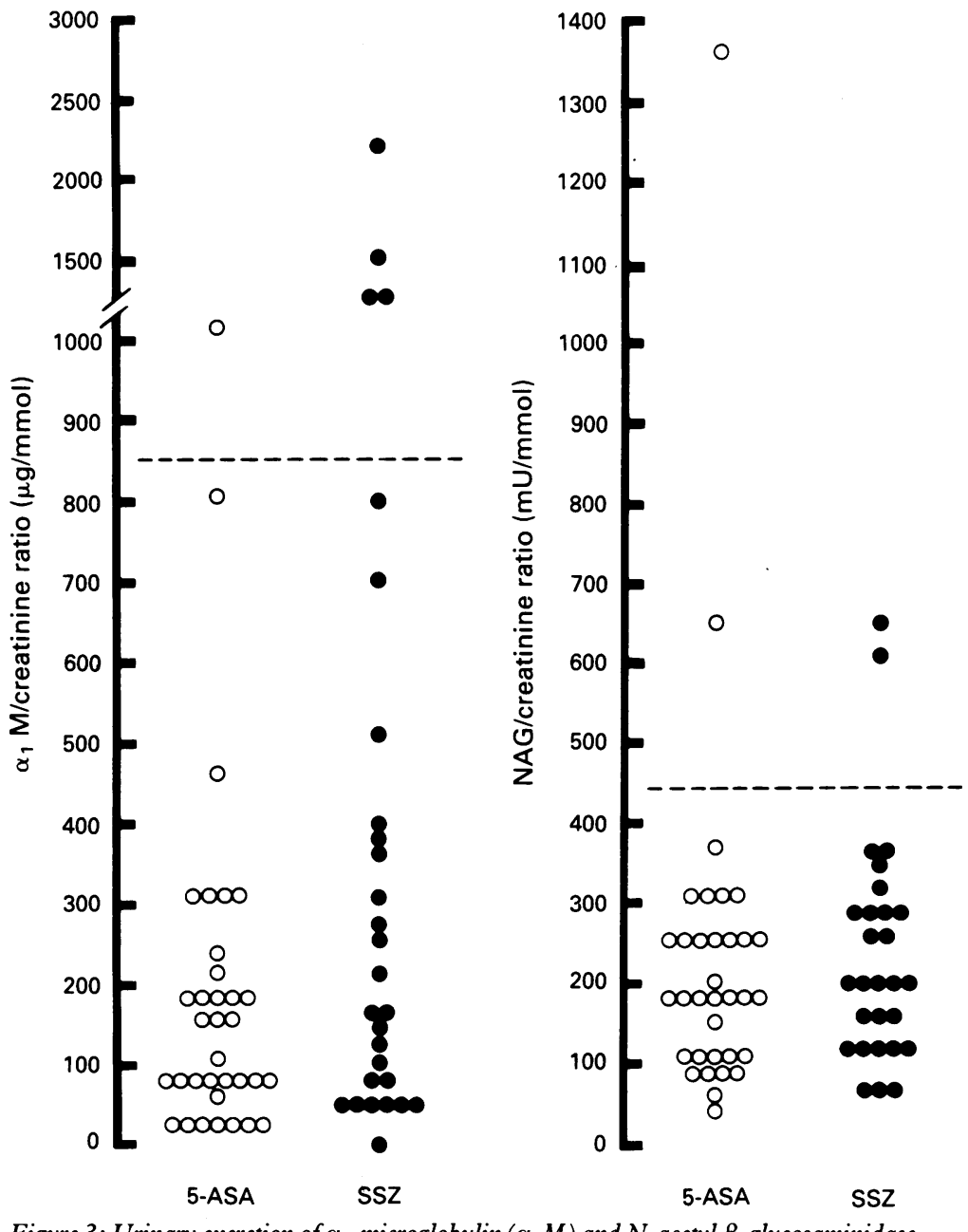

Figure 3: Urinary excretion of $\alpha_{1}$-microglobulin $\left(\alpha_{1} M\right)$ and $N$-acetyl- $\beta$-glucosaminidase (NAG) in patients maintained on mesalazine (5-ASA) and sulphasalazine (SSZ). Results are expressed as marker/creatinine concentration ratios. The upper limit of normal (95th centile) is shown by the dotted line. dent of dose and a number have occurred in patients previously exhibiting allergic reactions to sulphasalazine. In the only documented case in which rechallenge has been undertaken, low dose rechallenge with both mesalazine and sulphasalazine caused microscopic haematuria suggesting dose independent hypersensitivity to 5-ASA. ${ }^{3+}$

Clinical trials with mesalazine formulations have been more reassuring. In one early study of colitis relapse, two patients treated with mesalazine $2.4 \mathrm{~g}$ daily for four weeks developed minor rises in plasma creatinine concentrations. ${ }^{35}$ More recent studies, however, have not confirmed this finding ${ }^{36}$ and in a number of studies, patients in relapse have been treated with doses up to $4.8 \mathrm{~g}$ daily without untoward effect. ${ }^{37}$ Furthermore, a number of maintenance studies have shown no significant change in renal function on standard biochemical screening. ${ }^{38-10}$ In the only detailed study of tubular function in man, Diener et $a l^{27}$ found no evidence of continuing renal dysfunction in a group of nine patients with Crohn's disease maintained on mesalazine $1.5 \mathrm{~g}$ daily for up to 12 weeks.

In this study we have assessed renal function in a group of patients who have been maintained on delayed release mesalazine from six months to over six years. We have measured the urinary excretion of albumin and transferrin as these are sensitive indicators of early glomerular damage, ${ }^{67}$ and the excretion of NAG and $\alpha_{1}$ microglobulin as these are sensitive markers of tubular toxicity. ${ }^{89}$ NAG has been used extensively to identify and monitor potentially nephrotoxic drugs, ${ }^{8}$ its excretion increases in a dose dependent manner following the ingestion of aspirin and sodium salicylate ${ }^{18}$ and high concentrations are found in patients with established analgesic nephropathy. ${ }^{8}$ Using this battery of sensitive tests we were unable to find evidence that maintenance treatment with mesalazine was any more nephrotoxic than continued treatment with sulphasalazine. This was despite the fact that patients maintained on mesalazine were receiving twice the equivalent dose of 5-ASA as those maintained on sulphasalazine.

Although toxicity marker excretion ratios were unrelated to the type of maintenance drug treatment, a number of patients had marker excretion values above the 95th centile for healthy volunteers raising the possibility of mild glomerular and tubular dysfunction. Whether these values represent the upper extreme of normality or are related to the underlying colonic disease, long term medication, or other factors is not clear. Clinical evidence of renal dysfunction is unusual in patients with ulcerative colitis. Renal stones occur more commonly than in the general population ${ }^{+1}$ and, rarely, amyloidosis may occur. ${ }^{+2}$ Detailed pathological studies to detect subclinical renal disease have not been undertaken.

In conclusion, there is little doubt that mesalazine may cause nephrotoxic reactions. The available evidence suggests that in humans these are allergic in nature and independent of dose. They may therefore occur after the ingestion of all 5-ASA containing formulations. Within the current therapeutic dose range there is no have been reported in patients taking delays release mesalazine. ${ }^{32-34}$ Clinical presentation has been with acute nephritis, nephrotic syndrome, or renal failure. When undertaken, renal biopsy has usually shown interstitial nephritis, although minimal change nephropathy has been reported..$^{33}$ These reactions seem to be indepen- 
evidence to suggest dose dependent nephrotoxicity and in the present study long term maintenance treatment with delayed release mesalazine was no more nephrotoxic than continued treatment with sulphasalazine.

1 Riley SA, Turnberg LA. Sulphasalazine and the aminosalicylates in the treatment of inflammatory bowel disease. Quart 7 Med 1990; 75:551-62.

2 Dissanayake AS, Truelove SC. A controlled therapeutic tria of long-term maintenance treatment of ulcerative colitis with sulphasalazine. Gut 1973; 14: 923-6.

3 Calder IC, Funder CC, Green CR, Ham KN, Tange JD. Nephrotoxic lesions from 5-aminosalicylic acid. $B M \mathcal{F} 1972$ 1: $152-4$.

4 Bondesen S, Nielsen OH, Schou JB, et al. Steady-state kinetics of 5-aminosalicylic acid and sulphapyridine during sulphasalazine prophylaxis in ulcerative colitis. Scand $\mathcal{F}$ Sulphasalazine prophylaxis in

5 Stærk Laursen L, Stokholm M, Bukhave K, Rask-Madsen J, Lauritsen K. Disposition of 5-animosalicylic acid by olsalazine and three mesalazine preparations in patients with ulcerative colitis: comparison of intraluminal colonic concentrations, serum values, and urinary excretion. Gut 1990 31: $1271-6$.

6 Mogensen CE. Microalbuminuria as a predictor of clinical diabetic nephropathy. Kidney Int 1987; 31: 673-9.

7 Bernard AM, Ouled Amor AA, Goemaere-Vanneste J, et al. Microtransferrinuria is a more sensitive indicator of early glomerular damage in diabetes than microalbuminuria. Clin Chem 1988; 34: 9.

8 Price RG. Urinary enzymes, nephrotoxicity and renal disease. Toxicology 1982; 23: 99-134.

9 Walton C, Bodansky HJ, Wales JK, Forbes MA, Cooper EH Tubular dysfunction and microalbuminuria in insulin Tubular dysfunction and microalbuminuria in

10 Gabriel R. Time to scrap creatinine clearance? BMF 1986; 293: 1119-20.

11 Payne RB. Creatinine clearance: a redundant clinical investigation. Ann Clin Biochem 1986; 23: 243-50.

12 Ginsberg JM, Chang BS, Maltarese RA, et al. Use of singlevoided urine samples to estimate quantitative proteinuria. NEFM 1983; 309: 1543-6.

13 Husdan H, Rappoport A. Estimation of creatinine by the Jaffe reaction: a comparison of three methods. Clin Chem 1968; 14: $222-38$.

14 Lloyd DR, Hindle EJ, Marples J, Gatt JA. Urinary albumin measurement by immunoturbidimetry. Ann Clin Biochem measurement by

15 Catty D, Raykundalia C. ELISA and related enzyme immunoassays. In: Catty D, ed. Antibodies: a practical approach, vol 2. Oxford: IRL Press, 1989.

16 Schwab SJ, Christensen RL, Dougherty K, Klahr S. Quantitation of proteinuria by the use of protein-to-creatinine ratios in single urine samples. Arch Intern Med 1987; 147: 943-4.

17 Matthew H, Lawson AAH. Acute poisoning due to salicylate, phenacetin and paracetamol. In: Matthew H, Lawson AAH, eds. Treatment of common acute poisonings, 4th ed. Edinburgh: Churchill Livingstone, 1979: 82-93.

18 Lockwood TD, Bosmann HB. The use of urinary N-acetyl- $\beta$ glucosaminidase in human renal toxicology. II. Elevation of glucosaminidase in human renal toxicology. Il. Elevation of human excretion after aspirin and

19 Proctor RA, Kunin CM. Salicylate-induced enzymuria. $A m \mathcal{F}$ Med 1978; 65: 987-93.
20 Arnold L, Collins C, Starmer GA. The short-term effects of analgesics on the kidney with special reference to acetylsalicylic acid. Pathology 1973; 5: 123-34.

21 Sandler DP, Smith JC, Weinberg CR, et al. Analgesic use and chronic renal disease. NEFM 1989; 320: 1238-43.

22 Dubach UC, Rosner B, Stürmer T. An epidemiologic study of abuse of analgesic drugs. Effects of phenacetin and salicylate on mortality and cardiovascular morbidity (1968 to 1987). NEFM 1991; 324: 155-60.

23 Brander L, Kuhlback B, Niemiste M, Riska N. The effect of massive doses of PAS on renal function and electrolyte massive doses of PAS on renal function

24 Chester AC, Diamond LH, Schreiner GE. Hypersensitivity to salicylazosulfapyridine. Renal and hepatic toxic reactions. Arch Int Med 1978; 138: 1138-9.

25 Barbour VM, Williams PF. Nephrotic syndrome associated with sulphasalazine. $B M \mathcal{F}$ 1990; 301: 818 .

26 Koutras A, Daum F, Das KM, et al. Sulfasalazine and renal tubular function: lack of an effect. $\mathcal{F}$ Pediat Gastroenterol Nutr 1985; 4: 103-6.

27 Diener U, Tuczek H-V, Fischer C, Maier K, Klotz U. Renal function was not impaired by treatment with 5 -aminosalicylic acid in rats and man. Naunym-Schmiedeberg's Arch Pharmacol 1984; 326: 278-82.

28 Bilyard KG, Joseph EC, Metcalf R. Mesalazine: an overview of key preclinical studies. Scand $\mathcal{f}$ Gastroenterol 1990;25 of key preclinical

29 Christensen LA, Fallingborg J, Abildgaard K, et al. Topical and systemic availability of 5 -amino-salicylate: comparisons of three controlled release preparations in man. Alimen Pharmacol Therap 1990; 4: 523-33.

30 Calder IC, Funder CC, Green CR, Ham KN, Tange JD. Comparative nephrotoxicity of aspirin and phenacetin derivatives. $B M \mathcal{F} 1971$; 4: 518-21.

31 Hayllar J, Bjarnason I. Sulphasalazine in ulcerative colitis: in memoriam? Gut 1991; 32: 462-3.

32 Committee on Safety of Medicines. Nephrotoxicity associated with mesalazine (Asacol). Current Problems; No 30. London, with mesalazine (Asacol). Current Problem

33 Novis BH, Korzets Z, Chen P, Bernheim J. Nephrotic syndrome after treatment with 5-aminosalicylic acid. $B M \mathcal{F}$ 1988; 296: 1442 .

34 von Mühlendahl KE. Nephritis durch 5-Aminosalicylsäure. Dtsch Med Wocheschr 1989; 114: 236

35 Riley SA, Mani V, Goodman MJ, Herd ME, Dutt S, Turnber LA. Comparison of delayed-release 5-aminosalicylic acid (mesalazine) and sulphasalazine in the treatment of mild to moderate ulcerative colitis relapse. Gut 1988; 29: 669-74

36 Rachmilewitz D. Coated mesalazine (5-aminosalicylic acid) versus sulphasalazine in the treatment of active ulcerative colitis: a randomised trial. $B M \mathcal{F}$ 1988; 298: 82-6.

37 Schroeder KW, Tremaine WJ, Illstrup DM. Coated oral 5 -aminosalicylic acid therapy for mildly to moderately active 5-aminosalicylic acid therapy for mildy to moderately active
ulcerative colitis. A randomized study. NEFM 1987; 317: 1625-9.

38 Riley SA, Mani V, Goodman MJ, Herd ME, Dutt S, Turnberg LA. Comparison of delayed-release 5-aminosalicylic acid and sulphasalazine as maintenance treatment for patients with ulcerative colitis. Gastroenterology 1988; 94: 1383-9.

39 Dew MJ, Harries AD, Evans N, Evans BK, Rhodes J Maintenance of remission in ulcerative colitis with 5 -aminosalicylic acid in high doses by mouth. $B M \mathcal{F} 1983$; 287: 23-4.

40 Rutgeerts P. Mesalazine is as effective as sulphasalazine in maintaining ulcerative colitis in remission. Aliment Pharmacol Ther 1989; 3: 183-91.

41 Grossman MS, Nugent FW. Urolithiasis as a complication of chronic diarrhoeal disease. Am 7 Dig Dis 1967; 12: 491-8.

42 Rand JA, Brandt LJ, Baker NH, Lynch J. Ulcerative colitis complicated by amyloid. Am $\mathcal{F}$ Gastroenterol 1980; 74: 185-8. 